\title{
A construção da campanha eleitoral majoritária no HGPE: uma análise comparada das estratégias usadas pelos presidenciáveis de 2014
}

\author{
Michele Goulart Massuchin' \\ Camilla Quesada Tavares ${ }^{2}$ \\ Fernanda Cavassana de Carvalho ${ }^{3}$ \\ Regiane Soares Lima4
}

\section{Resumo}

Este artigo tem por objetivo discutir as diferenças na apropriação do Horário Gratuito de Propaganda Eleitoral (HGPE) pelos partidos e candidatos na disputa majoritária à Presidência da República em 2014. A propaganda televisiva é o principal recurso de campanha utilizado em eleições de grande porte, sendo que tanto o conteúdo quanto o formato são relevantes para compreender o modo como a disputa se estrutura. Analisa-se o conteúdo apresentado pelos dois principais candidatos - Dilma Rousseff (PT) e Aécio Neves (PSDB) - considerando as estratégias, o apelo, os formatos, o tipo de orador e a mensagem geral de campanha. A metodologia utilizada é quantitativa de análise de conteúdo, sendo que este artigo parte de duas hipóteses: a) o segundo turno torna-se mais negativo, com maior ênfase na imagem do candidato e com uma campanha mais voltada para as emoções; b) a estruturação da campanha dos candidatos se dá de modo diferente, evidenciando características e formatos distintos.

Palavras-chave: Eleições 2014, HGPE majoritário, estratégias de campanha.

1 Professora do curso de Jornalismo da UFMA. Doutora em Ciência Política pela UFSCar e mestre em Ciência Política pela UFPR. Pesquisadora do Núcleo de Pesquisa em Comunicação, Política e Opinião Pública (CPOP/UFPR). E-mail: mimassuchin@gmail.com.

2 Doutoranda em Comunicação pela UFF e mestre em Ciências Sociais Aplicadas pela UEPG. Professora do curso de Jornalismo da UEPG. E-mail: camilla.tavares8@gmail.com.

${ }^{3}$ Doutoranda em Ciência Política e mestre em Comunicação pela UFPR. Professora do curso de Comunicação Organizacional da UTFPR. Pesquisadora do CPOP. E-mail: fercavassana@hotmail.com.

4 Graduanda em Ciências Sociais na UFPR. Pesquisadora do CPOP. E-mail: r.soalima@gmail.com. 
A construção da campanha eleitoral majoritária no HGPE: uma análise comparada das estratégias usadas pelos presidenciáveis de 2014 - Michele Goulart Massuchin, Camilla Quesada Tavares, Fernanda Cavassana de Carvalho e Regiane Soares Lima

\section{Introdução}

O Horário Gratuito de Propaganda Eleitoral (HGPE) é o principal recurso que os partidos e candidatos possuem para se apresentarem aos eleitores. Juntamente com as informações recebidas dos meios de comunicação tradicionais, a propaganda compõe também o ambiente informacional dos indivíduos em período eleitoral. Com o HGPE, que tem início 45 dias antes da eleição, há, portanto, o acréscimo de um tipo específico de informação, agora produzida diretamente pelos candidatos e partidos (CERVI, 2010).

A propaganda televisiva tem a função, segundo Albuquerque (1999), de formar a imagem dos candidatos, debater temas e também falar da própria campanha. Pode-se acrescentar também que ele organiza o processo eleitoral e, de forma mais enfática, é produzido tendo como foco os eleitores indecisos (FIGUEIREDO, 2008). Neste sentido, a maneira como os candidatos ocupam este espaço é importante na construção da campanha, principalmente ao escolherem determinados formatos e estratégias.

Os principais candidatos que disputam uma eleição têm como meta alcançar o sucesso eleitoral traduzido por meio da angariação do maior número de votos possíveis (BENOIT et al, 2007). Para isso, tentam obter visibilidade durante o período eleitoral a partir de determinadas estratégias que permeiam a propaganda dos candidatos, em especial no HGPE. Independentemente do tipo de propaganda publicidade impressa, campanha de rua, televisão ou internet - a elite política tenta convencer o eleitor, a partir de técnicas e estratégias persuasivas, quem é o mais preparado para o cargo. Portanto, faz-se necessário observar como a campanha televisiva é construída e estruturada pelas equipes de marketing para entender como os candidatos pretendem ser vistos pelos eleitores.

Neste sentido, este artigo tem o objetivo de analisar como a propaganda feita por meio do HGPE foi estruturada pelas duas principais candidaturas na disputa presidencial de 2014: Dilma Rousseff (PT) e Aécio Neves (PSDB). Considerando o primeiro e o segundo turno, avaliam-se as diferenças ao longo do tempo e, também, as similaridades e divergências entre os candidatos. Para isso tem-se como base o conteúdo de todos os programas exibidos no horário noturno entre 19 de agosto e 24 de outubro. A coleta de dados foi realizada pelo Núcleo de Pesquisa em Comunicação Política \& Opinião Pública da UFPR (CPOP) e para esta discussão trabalha-se com as seguintes variáveis - algumas sobre a forma e outras sobre conteúdo: tempo dos segmentos, formato, orador, mensagem, apelo e estratégias. 
A partir da análise quantitativa de conteúdo, pretende-se testar as seguintes hipóteses sobre o modo como as campanhas são produzidas e apresentadas aos eleitores: a) enquanto o primeiro turno tende a ser mais temático e programático, o segundo turno tende a ser mais negativo, com maior ênfase na imagem do candidato e baseado em um discurso emocional; b) a estruturação da campanha de ambos os candidatos se dá de modo diferente, evidenciando características distintas quanto à apropriação do HGPE. 0 texto está dividido em cinco partes. Inicialmente, discutem-se algumas questões chaves do HGPE e, na sequência, as estratégias a serem estudadas. Também são feitos alguns aportes metodológicos antes de apresentar a análise, a qual é estruturada primeiramente com uma discussão comparada entre os dois turnos e, depois, entre os dois principais candidatos. Por fim, têmse as considerações finais.

\section{O HGPE enquanto recurso dos partidos e candidatos}

A propaganda eleitoral está presente nos meios de comunicação desde o início do século XX. No Brasil, o HGPE, tal como conhecemos hoje, surge em 1962 e sofre nova regulamentação em 1982 com o fim da ditadura militar (PANKE e CERVI, 2011). Porém, para Albuquerque (1999), é somente a partir de 1985 que o horário eleitoral se constitui em um instrumento efetivo do jogo democrático. Assim, a campanha eleitoral de 1989 para a Presidência da República fez com que o HGPE ganhasse força e, desde então, as campanhas estão cada vez sofisticadas, com um alto grau de profissionalização para atrair os eleitores.

Atualmente são contratados especialistas em marketing e publicidade para que as campanhas fiquem cada vez mais profissionais, o que se constitui como uma das características da fase de modernização das campanhas (NORRIS, 2004). Outra mudança é no aumento da personalização da política e falta de vínculo partidário (MANCINI e SWANSON, 1995; DE LA TORRE, 2009; LAVAREDA, 2009). Hoje, o que diferencia um candidato de outro são os aspectos pessoais de cada um, tornando as campanhas televisivas mais personalistas (TAVARES, 2013). Segundo Dias (2005), as campanhas profissionais são comparadas a mercados: os partidos, por meio dos candidatos, tentam vender seus "produtos", enquanto que os consumidores - os eleitores - usam o voto como moeda de troca, principalmente pela volatilidade das preferências.

A disputa eleitoral de 1989 também despertou um interesse maior em analisar os efeitos dos meios de comunicação na política. Este 
A construção da campanha eleitoral majoritária no HGPE: uma análise comparada das estratégias usadas pelos presidenciáveis de 2014 - Michele Goulart Massuchin, Camilla Quesada Tavares, Fernanda Cavassana de Carvalho e Regiane Soares Lima

interesse se deu em diversos aspectos, desde o "desempenho performático do candidato vitorioso, à influência dos programas eleitorais na formação das intenções de voto e à interferência da mídia no processo eleitoral" (FIGUEIREDO, 2007, p. 2). No casto deste estudo, a análise se dedica ao primeiro aspecto, ou seja, o desempenho do candidato e como os programas são construídos.

A crescente importância da mídia para o processo eleitoral vem sendo apontada por alguns autores como um dos motivos para o enfraquecimento, por exemplo, dos partidos políticos e bases ideológicas (MAIR, 2003; DIAS, 2009), abrindo espaço para a personalização e o prevalecimento de estratégias (CARREIRÃO, 2007). Essa nova configuração das campanhas, mais especificamente do HGPE, que se assemelha ao espetáculo (ALBUQUERQUE, 1999; RUBIM, 2004), foi alvo de algumas críticas. Panke e Cervi (2011) explicam que os programas do horário eleitoral perderam credibilidade política justamente por esse caráter de espetacularização, o que tem a ver com a negação por parte dos eleitores sobre a veracidade dessas informações.

Para Gomes (2001), o eixo central das campanhas é a informação. Porém, isso se perdeu com o passar dos anos, culminando na crescente utilização do mecanismo de persuasão, sendo a informação apenas um degrau dentro do processo. Ou seja, há informação, mas o HGPE tem a função primordial de persuadir por meio do conteúdo e para isso se utiliza de formatos diferenciados, como jingles e animação, por exemplo. A crítica feita por Gomes (2011) é verificada na prática, quando se observa, por exemplo, que boa parte do tempo dos programas é destinada à formação da imagem do candidato em detrimento de apresentação e discussão de propostas de interesse público (CERVI e MASSUCHIN, 2011).

Apesar das críticas, o horário eleitoral ainda integra o principal espaço de campanha midiatizado que partidos possuem para apresentar seus candidatos. O HGPE é a principal forma de mídia controlada diretamente pelos dirigentes partidários para demonstração dos candidatos e formação da imagem para o eleitor, ficando a cargo do partido e dos recursos disponíveis de que forma isso ocorrerá. A diferença de recursos, assim como a autonomia dos partidos, também define as formas e apropriações do HGPE, as quais se pretende analisar na sequência.

Além disso, ele é o principal marco do início da campanha. Segundo Cervi (2010), o início do HGPE marca o "tempo da política", por ser o momento em que o eleitor mediano começa a prestar atenção 
na política e utiliza esse recurso para construir suas preferências partidárias. Até o início do horário eleitoral, as discussões envolvendo temas públicos, partidos e candidatos surgem e podem se limitar a espaços públicos, não conseguindo entrar na esfera privada das pessoas, mas o HGPE consegue fazer isso, por ser veiculado nos meios de comunicação de massa durante a programação televisiva.

O HGPE também tem relevância na configuração das coligações. Por saberem da importância para a disputa (BORBA, 2014), os partidos buscam coligações para ganharem mais tempo no rádio e televisão. A distribuição de tempo obedece ao tamanho das bancadas nas câmaras legislativas, norma estipulada pelo Tribunal Superior Eleitoral (TSE). Portanto, é o partido que controla seu tempo de televisão e a subdivisão entre os candidatos depende de critérios distributivos das forças internas do partido e da elite partidária. Para Albuquerque, Steibele Carneiro (2008) o "HGPE se apresenta como um fator de fortalecimento dos partidos políticos, uma vez que faz todos os candidatos dependerem deles para obter acesso ao rádio e à televisão durante as campanhas eleitorais" (ALBUQUERQUE, STEIBEL e CARNEIRO, 2008, p. 460).

O horário eleitoral representauma forma mais democrática de pôr em pauta a eleição, possibilitando a todo candidato um tempo nem que seja o mínimo obrigatório dividido igualmente - de aparição no rádio e televisão para se apresentar ao eleitor. Para Miguel (2005), essa é uma das principais vantagens do modelo brasileiro de campanha, visto ainda que qualquer tipo de propaganda paga não ser permitida.

\section{O HGPE nas campanhas eleitorais: estratégias e tematização}

Os primeiros estudos sobre estratégias no HGPE no Brasil datam do início da década de 1990. Colling (2007) investigou como se deu a produção bibliográfica que abordava as eleições de 1989 a 2002 e verificou que o HGPE apareceu como segundo objeto mais estudado entre os 195 trabalhos revisados (entre teses, dissertações e artigos). Deste total, 54 trabalhos tiveram o HGPE como foco de estudo, ficando atrás apenas de análises voltadas ao Jornalismo. A pesquisa de Aldé, Chagas e Santos (2013) também analisa as principais temáticas de teses e dissertações de 1992 a 2012. Embora não dividam por objetos de análise, os autores identificam que há uma produção considerável de pesquisas sobre Mídia e Eleições (119 trabalhos no total) e 
A construção da campanha eleitoral majoritária no HGPE: uma análise comparada das estratégias usadas pelos presidenciáveis de 2014 - Michele Goulart Massuchin, Camilla Quesada Tavares, Fernanda Cavassana de Carvalho e Regiane Soares Lima

Propaganda e Marketing Político (87), duas grandes áreas que podem envolver os estudos sobre horário eleitoral televisivo.

As pesquisas seguem objetivos distintos, mas de alguma forma versam sobre o modo com o HGPE é estruturado, quais suas características e como se relaciona com outros modos de campanha. 0 estudo de Reis (2003), por exemplo, verifica se as pesquisas de opinião pública interferiram no que os principais candidatos à prefeitura de São Paulo discursaram no HGPE de 2000; com temática parecida, Cervi, Massuchin e Tavares (2012) desenvolveram uma pesquisa sobre circularidade das agendas, incluindo a política (HGPE), midiática (Folha de S. Paulo e 0 Estado de S. Paulo) e do público (opinião pública). Oliveira (2008) escolheu o HGPE como objeto de estudo para investigar como o marketing político e eleitoral era utilizado no HGPE e interferia na construção do eleitor como um cidadão político. Dias (2005; 2009; 2013) centrou seu estudo em analisar a presença dos partidos políticos no horário eleitoral. Figueiredo et al (1997); Albuquerque (1999); Figueiredo e Aldé (2003); Panke e Cervi (2011); Dias (2014) desenvolveram trabalhos que propõem metodologias para a análise de programas do HGPE, tanto em âmbito quantitativo quanto qualitativo.

Por fim, Albuquerque (1999); Schmmitt, Carneiro e Kucshnir (1999); Porto e Guazina (1995) Almeida (2007); Carvalho (2007); Lourenço (2009); Machado (2009); Souza, Cervi e Santos (2009); Oliveira (2010); Cervi e Massuchin (2011); Panke et al (2011); Borba (2012; 2015); Tavares (2013); Massuchin e Tavares (2014), entre outros autores, desenvolveram pesquisas que analisavam as estratégias discursivas dos candidatos no HGPE, os temas mais recorrentes e os formatos utilizados nos programas dos principais partidos.

Sob a perspectiva de Figueiredo et al (1997) e Albuquerque (1999), os programas do horário eleitoral são complexos e apresentam diferentes tipos de conteúdo em cada trecho. Dentre eles aparecem os temáticos e também as estratégias de persuasão (Albuquerque, 1999), visto que a propaganda na televisão integra a campanha, que tem como objetivo final angariar votos. Ressalta-se que este trabalho não faz nenhuma inferência quanto ao resultado e impacto do HGPE estudado e se centra na análise do conteúdo, pensando na sua produção.

A maneira como o HGPE é estruturado depende de vários fatores. Holtz-Bacha et al (2012) argumentam que os contextos do país e da eleição são variáveis que influenciam nas estratégias empregadas. Por isso, as campanhas se estruturam de maneira diferente dependendo do país, da cultura e do sistema de mídia (HOLTZ-BACHA 
et al, 2012). Restringindo-se ao caso brasileiro, Figueiredo et al (1997) defendem que, durante a campanha, os candidatos se dedicam a uma argumentação de natureza ficcional - ou seja, a partir de percepções sobre a realidade (OLIVEIRA, 2010), pois se baseiam na construção de um mundo atual possível e, com base nele, projetam um novo e bom mundo futuro possível. Holtz-Bacha et al (2012) reafirmam essa ideia e destacam a apresentação dos candidatos como sendo os solucionadores dos problemas atuais. Essa é uma função muito visível nos programas do horário eleitoral, principalmente de candidatos desafiantes, que destacam o discurso de mudança.

Além de ser um espaço midiático privilegiado da elite política, Oliveira (2010) observa que o HGPE pauta e tematiza boa parte das discussões políticas do período, tornando-se importante, então, identificar sobre o que os candidatos falam para ter conhecimento de parte significativa do conteúdo que está circulando na sociedade em épocas eleitorais. Porto e Guazina (1995) identificaram que, durante a eleição de 1994, o discurso geral dos candidatos no horário eleitoral forneceu ao eleitor diferentes diagnósticos sobre a situação daquele momento do país, tendo o Plano Real o lugar mais importante dentre as temáticas mais discutidas. Apesar disso, até há poucas eleições, essa abordagem ficava em segundo plano, priorizando a personalização e construção da imagem do candidato (CERVI e MASSUCHIN, 2011; PETHS, 2013). Porém, estudos recentes identificaram uma variação dessa normativa, pelo menos em contextos locais (MASSUCHIN e TAVARES, 2014).

Outra estratégia que permeia o horário eleitoral diz respeito à estrutura dos programas. Fausto Neto (1990) pontua a importância dos gêneros televisivos como recursos de legitimação do discurso político (ALBUQUERQUE, 2003). Recorrer a formatos típicos do jornalismo, como os telejornais, suaviza a quebra na programação imputada pelo início dos programas, que estão no meio da grade. Oliveira (2005) analisou a campanha de Jarbas Vasconcelos e Humberto Costa para governador de Pernambuco em 2002. A autora conclui que, embora não haja apenas os gêneros jornalísticos, recorrer a eles ajuda na comunicação, pois são formatos reconhecidos do eleitor comum, além de dar maior credibilidade à enunciação.

Do ponto de vista do discurso, Figueiredo et al (1997) propõem dividir as estratégias discursivas do ponto de vista do mandatário (dentre eles, a ênfase em realizações e a associação à administração em curso) e do desafiante (dentre o que nos interessa, o apelo de mudança; a ofensiva quanto a temas; ataques à administração em curso; ataques ao adversário). 0 estudo de Porto e Guazina (1995) confirma essa 
A construção da campanha eleitoral majoritária no HGPE: uma análise comparada das estratégias usadas pelos presidenciáveis de 2014 - Michele Goulart Massuchin, Camilla Quesada Tavares, Fernanda Cavassana de Carvalho e Regiane Soares Lima

diferença de apropriação de estratégias, dependendo do lugar que se ocupa no pleito. Nas eleições de 1994, o candidato apoiado pelo governo - Fernando Henrique Cardoso - foi o que menos criticou os outros candidatos ou instituições, segundo constata os autores. Mas embora se faça essa divisão e se identifique essa tendência em alguns casos, nem sempre os candidatos recorrem a estratégias típicas da sua posição no pleito, conforme identificaram os próprios Figueiredo et al (1997).

Cada uma das estratégias observadas no HGPE pode ser pesquisada de maneira segmentada. Por exemplo, os estudos de Lourenço (2009) e Borba (2012) se dedicam a investigar como se configura a propaganda negativa no horário eleitoral. A discussão de Tavares (2014) busca mapear quem são as personalidades que manifestam apoio ao candidato. Há ainda os estudos que se dedicam a investigar a retórica e apelo empregados pelos candidatos. Machado (2009) procurou identificar as estratégias retóricas presentes nos discursos dos candidatos à reeleição em 1998 - Fernando Henrique Cardoso (PSDB) - e 2006 - Luiz Inácio Lula da Silva (PT). A autora identifica que, embora haja diferenças na conjuntura política, é possível encontrar focos de convergência entre os discursos, como é o caso de explorar o uso da gestão em curso em favor da candidatura e de traduzir o mundo atual a partir de uma agenda positiva. Já Miguel (2010) buscou entender os apelos discursivos presentes nas propagandas eleitorais das eleições proporcionais do Distrito Federal. Após identificadas várias das vertentes de estudos sobre HGPE, apresenta-se, na sequência, a metodologia utilizada na análise deste artigo.

\section{Metodologia e discussão das variáveis}

Os dados desta pesquisa são referentes aos programas veiculados no horário eleitoral televisivo de Dilma Rousseff (PT) e Aécio Neves (PSDB), no primeiro e segundo turno da campanha de 2014. Eles foram coletados pelos integrantes do Núcleo de Pesquisa em Comunicação Política \& Opinião Pública da Universidade Federal do Paraná (CPOP/UFPR) ${ }^{5}$. A metodologia utilizada é quantitativa de análise de conteúdo, já que o objetivo geral do trabalho é verificar padrões e poder compará-los (CERVI, 2009), principalmente com

\footnotetext{
${ }^{5}$ Os alunos de graduação e pós-graduação passam anualmente por treinamento para realizar a coleta de dados. As autoras aproveitam este espaço para agradecer aos integrantes do CPOP pelo trabalho de coleta e codificação dos dados realizado de modo coletivo.
} 
pesquisas já realizadas sobre o tema. As categorias de análise adotadas são baseadas no trabalho de Figueiredo et al (1997), com destaque para as que compõem diretamente o estudo: estratégias,apelo, formatos, orador e mensagem geral ${ }^{6}$.

Em 2014, Dilma Rousseff tinha um total de 11 minutos e 48 segundos no primeiro turno, e Aécio Neves dispunha de 4 minutos e 31 segundos. Já no segundo turno, o tempo é igualitário aos candidatos, sendo de 10 minutos para cada7 ${ }^{7}$. Para fins de análise, os programas do HGPE são divididos por segmentos. O segmento refere-se a uma unidade de análise do programa, ou seja, um trecho que possui autonomia discursiva (ALBUQUERQUE, 1999), onde se mantém o mesmo cenário, temática ou orador. Quando pelo menos duas dessas características se alteram, muda-se o segmento. No caso das eleições presidenciais de 2014, o número total de segmentos dos programas dos dois principais candidatos foi de 265 e178 (1ํ e $2^{\circ}$ turno, respectivamente) para Dilma Rousseff e 139 e 154 (1ํ e $2^{\circ}$ turno, respectivamente) para Aécio Neves.

A primeira característica a ser observada são as estratégias discursivas. No total, 11 variáveis integram esse eixo e são dummys, ou seja, de presença ou ausência no segmento. Um segmento pode ter mais de uma estratégia empregada, e elas tendem a indicar, de maneira geral, a construção do discurso dos candidatos.

\section{Quadro 1 - Variáveis de estratégia discursiva}

\begin{tabular}{|l|l|}
\hline Nome & Descrição \\
\hline Uso do cargo & Quando cita o cargo que ocupa/ocupou. \\
\hline $\begin{array}{l}\text { Ênfase na } \\
\text { administração } \\
\text { em curso }\end{array}$ & $\begin{array}{l}\text { Quando o candidato se vincula à administração } \\
\text { em curso ou a ações desenvolvidas nela, desde } \\
\text { que na mesma esfera do cargo em disputa. }\end{array}$ \\
\hline $\begin{array}{l}\text { Associação à } \\
\text { administração de } \\
\text { outra esfera }\end{array}$ & $\begin{array}{l}\text { Cita governantes que ocupam cargos em outras } \\
\text { esferas de poder. }\end{array}$ \\
\hline Apoio de lideranças & $\begin{array}{l}\text { Quando aparecem líderes de organizações } \\
\text { políticas manifestando apoio ao candidato. }\end{array}$ \\
\hline $\begin{array}{l}\text { Apoio de lideranças } \\
\text { da sociedade civil } \\
\text { organizada }\end{array}$ & $\begin{array}{l}\text { Apoio de líderes de entidades representativas, } \\
\text { mas não políticas. }\end{array}$ \\
\hline Apoio do patrono & $\begin{array}{l}\text { Apoio de líderes políticos ligados à história do } \\
\text { candidato. }\end{array}$ \\
\hline
\end{tabular}

\footnotetext{
${ }^{6} 0$ livro de códigos utilizado na coleta possui 30 variáveis no total.

${ }^{7}$ Lembrando que durante a campanha, há duas inserções por dia do HGPE na grade de programação - uma na hora do almoço e outra no horário nobre.
} 
A construção da campanha eleitoral majoritária no HGPE: uma análise comparada das estratégias usadas pelos presidenciáveis de 2014 - Michele Goulart Massuchin, Camilla Quesada Tavares, Fernanda Cavassana de Carvalho e Regiane Soares Lima

\begin{tabular}{|l|l|}
$\begin{array}{l}\text { Menção ao partido ou } \\
\text { coligação }\end{array}$ & $\begin{array}{l}\text { Quando é mencionado oralmente o partido ou } \\
\text { coligação. }\end{array}$ \\
\hline Apelo a mudanças & $\begin{array}{l}\text { Quando se defende expressamente a mudança do } \\
\text { grupo político ou partido que está no poder. }\end{array}$ \\
\hline $\begin{array}{l}\text { Ofensiva quanto a } \\
\text { temas }\end{array}$ & $\begin{array}{l}\text { Quando se predomina a crítica a temas de política } \\
\text { pública. }\end{array}$ \\
\hline $\begin{array}{l}\text { Ataques à } \\
\text { administração }\end{array}$ & $\begin{array}{l}\text { Quando ataca decisões tomadas ou políticas } \\
\text { públicas implementadas pela atual } \\
\text { administração. }\end{array}$ \\
\hline $\begin{array}{l}\text { Ataque aos } \\
\text { adversários }\end{array}$ & $\begin{array}{l}\text { Quando há o ataque direto a governantes, } \\
\text { membros da equipe e demais concorrentes ao } \\
\text { cargo. }\end{array}$ \\
\hline
\end{tabular}

Fonte: Figueiredo et al (1997).

A variável apelo é categórica e serve para identificar a que conteúdo persuasivo o candidato recorre para construir a mensagem. Os segmentos podem ser classificados a partir de cinco possibilidades: apelo pragmático (quando apresenta uma proposição de política pública); apelo ideológico (quando está baseado em preceitos ou dogmas ideológicos); apelo político (quando o apelo é restrito à defesa de uma posição do partido ou grupo político); apelo emocional (quando a mensagem é desprovida de conteúdo político, pragmático ou ideológico, apelando-se para aspectos simbólicos); e apelo documental/credibilidade da fonte (quando há o predomínio do argumento de autoridade).

A próxima variável diz respeito aos formatos. Ela serve para identificar em qual formatação de programa aquele segmento foi gravado, tendo-se desde aqueles ligados à publicidade até ao jornalismo. Ao todo, são 9 categorias: pronunciamento do candidato; documentário; telejornal; entrevista; vídeo clipe/jingle; ilustração/animação; chamada; "Povo Fala" (quando aparece uma sequência de populares, "quase" anônimos) e depoimentos (de personagens conhecidos do grande público).

Utiliza-se, também, a variável orador dominante, responsável por indicar quem é o mensageiro do conteúdo veiculado no segmento. Aqui, são usadas como categorias: o candidato; o candidato à vice; o patrono político (quando houver a fala de personalidade política que tenha vínculo à carreira política do candidato); garoto propaganda; âncora (apresentador semelhante aos de telejornais); líder partidário (personalidade de liderança partidária sem, necessariamente, ter relação com a história política do candidato); popular (pessoa sem reconhecimento público); personagem/ficção (uso de bonecos ou 
personagens fictícios); personalidade (figura pública, artistas, cantores, jogadores famosos, por exemplo); off locutor (mensagem falada sem identificação do orador); off cantor (mensagem cantada sem identificação do orador); e instrumental (quando há somente notas sonoras).

Por fim, apresenta-se a variável mensagem geral, que tem por objetivo avaliar o que predomina em cada segmento, sendo, portanto, também uma variável categórica. No total, 24 categorias a integram, divididas em três grandes eixos: 1) apresentação de políticas públicas; 2) formação da imagem; 3) meta campanha ${ }^{8}$. Neste caso, cada segmento é classificado em apenas uma possibilidade, não sendo permitida mais de uma temática no mesmo trecho. Conhecidas as variáveis que serão analisadas dentro dos programas eleitorais dos principais candidatos à Presidência de 2014, apresentam-se os resultados da análise.

\section{A construção da campanhaem2014: comparando os dois turnos eleitorais}

A análise, neste tópico, é construída de modo comparado, indicando as diferenças e similaridades encontradas na forma como a propaganda televisiva se distribui no primeiro e segundo turno. 0 objetivo é testar a hipótese de que os modos de apropriação do espaço no HGPE são diferentes nos dois momentos que compõem a campanha, sendo que no segundo turno a propaganda tende a ser mais negativa, com ênfase na imagem do candidato e mais voltada às emoções em contraposição ao pragmatismo. A discussão é construída sempre evidenciando a comparação entre ambos os períodos ao analisar as cinco características apontadas acima.

\section{a. Segmentação da propaganda televisiva}

A tabela a seguir mostra os dados descritivos sobre o tempo e o número de segmentos em cada um dos períodos, considerando apenas

8 Integram o eixo de política pública as seguintes temáticas: segurança pública, saúde, educação, tributária, infraestrutura e saneamento básico, economia, desenvolvimento/planejamento urbano, esporte/cultura/lazer, transporte, meio ambiente, emprego, orçamento, criança, idoso, mulher, funcionalismo, agricultura, bem estar social, cardápio (conjunto de políticas), outra. Dentre as possibilidades de imagem, têm-se: imagem da cidade e região metropolitana, do estado, do país, do candidato, do partido, do adversário e do eleitor. Por fim, no eixo de meta campanha - que se refere a assuntos do próprio cotidiano da campanha - estão: pesquisa eleitoral, cenas externas da campanha, apelos ao engajamento do eleitor, pedagogia do voto, agenda, debate, irregularidade na campanha. 
A construção da campanha eleitoral majoritária no HGPE: uma análise comparada das estratégias usadas pelos presidenciáveis de 2014 - Michele Goulart Massuchin, Camilla Quesada Tavares, Fernanda Cavassana de Carvalho e Regiane Soares Lima

as campanhas de Dilma Rousseff e Aécio Neves. Ao todo, o material analisado aqui é composto por 404 segmentos no primeiro turno contra 332 no segundo. Foram observados o total de 16989 segundos (283 minutos) na primeira parte da campanha e 18387 segundos (306 minutos) na segunda etapa ${ }^{9}$. Relacionando o tempo em segundos com a quantidade de segmentos identificados em uma e outra parte da campanha, nota-se uma propaganda mais segmentada no primeiro turno do que no segundo, em que tanto a média quanto a mediana são maiores.

\section{Tabela 1. Distribuição do tempo e média entre primeiro e segundo} turno

\begin{tabular}{llr}
\hline Primeiro turno & N & 404 \\
& Media & 42,05 \\
& Mediana & 31,00 \\
& Desvio Padrão & 41,540 \\
& Soma & 16989 \\
Segundo turno & N & 332 \\
& Media & 55,38 \\
& Mediana & 47,50 \\
& Desvio Padrão & 40,138 \\
& Soma & 18387 \\
\hline
\end{tabular}

Nota:Teste T de diferença de média: 4,39 (sig.: $0,000)$.

Fonte: Núcleo de Pesquisa em Comunicação Política e Opinião Pública (CPOP)

Essa diferença já evidencia uma característica que distingue ambos os períodos, principalmente porque o teste $t$ de média mostrouse significativo $(0,000)$, indicando diferença entre a média de tempo dos segmentos em ambos os turnos. Notadamente, a campanha apresentou segmentos mais longos (55 segundos em média) no segundo turno em relação ao primeiro (42 segundos). Essa menor estratificação da campanha também é uma estratégia dos partidos e candidatos que optaram por uma propaganda mais unificada ao longo do tempo. É o caso, por exemplo, de programas "tematizados", focados na saúde, educação ou economia, com pouca alteração de temas. Do mesmo modo, pronunciamentos longos dos candidatos, também caracterizam essa mudança identificada.

\footnotetext{
${ }^{9}$ A diferença entre o tempo total destinado aos partidos e coligações e o tempo categorizado diz respeito à ausência de categorização para vinhetas e transições entre um e outro segmento.
} 
Ainda que o segundo turno seja, de fato, o mais decisivo, a propaganda tem sido menos segmentada e mais homogênea, destacando que essa variação pode ter menos relação com o financiamento de campanha - afinal a mudança se dá ao longo do tempo na mesma disputa - e mais com a estratégia de apresentação dos candidatos e de seus temas e agendas. Porém, em termos de formato da propaganda, não há grandes mudanças nos mais utilizados em ambos os períodos, como se pode ver na sequência.

\subsection{Formatos televisivos: a produção e os formatos jornalísticos}

Ainda que os segmentos tendam a ser mais longos, a apresentação da propaganda não muda. Pelo menos são esses os resultados obtidos ao relacionar os diferentes formatos com a distribuição do primeiro e segundo turno. 0 que se tem é uma variação muito pequena entre as variáveis turno e formato, com um quiquadrado de 12,704 e índice de significância de 0,176, ambos acima do limite crítico. Portanto, os formatos tendem a se manter mesmo com a mudança no período de campanha.

Tabela 2. Formatos televisivos no HGPE do primeiro e segundo turno

\begin{tabular}{l|r|r|r|r|r|r|r|r}
\hline & \multicolumn{3}{|c}{ Primeiro turno } & \multicolumn{3}{c}{ Segundo turno } & \multicolumn{2}{c}{ Total } \\
\cline { 2 - 9 } & $\mathrm{N}$ & Perc. & R.p & N & Perc. & R.p & N & Perc. \\
\hline Pron. candidato & 109 & $27 \%$ & 0,5 & 81 & $24,4 \%$ & $-0,5$ & 190 & $\mathbf{2 5 , 8 \%}$ \\
\hline Documentário & 64 & $15,8 \%$ & 0,3 & 49 & $14,8 \%$ & $-0,3$ & 113 & $\mathbf{1 5 , 4 \%}$ \\
\hline Telejornal & 70 & $17,3 \%$ & 0,4 & 51 & $15,4 \%$ & $-0,5$ & 121 & $\mathbf{1 6 , 4 \%}$ \\
\hline Entrevista & 14 & $3,5 \%$ & 0,7 & 7 & $2,1 \%$ & $-0,8$ & 21 & $2,9 \%$ \\
\hline Vídeo clipe/jingle & 27 & $6 \%$ & -1 & 33 & $9,9 \%$ & 1,1 & 60 & $\mathbf{8 , 2 \%}$ \\
\hline Ilustração/animação & 50 & $12,4 \%$ & 0,9 & 30 & $9 \%$ & -1 & 80 & $\mathbf{1 0 , 9 \%}$ \\
\hline "Povo Fala" & 24 & $5,9 \%$ & $-0,6$ & 25 & $7,5 \%$ & 0,6 & 49 & $6,7 \%$ \\
\hline Depoimentos/personagens & 26 & $6,4 \%$ & $-0,9$ & 30 & $9 \%$ & 0,9 & 56 & $7,6 \%$ \\
\hline Chamada & 12 & $3 \%$ & $-1,3$ & 20 & $6 \%$ & 1,5 & 32 & $4,3 \%$ \\
\hline Outros & 8 & $2 \%$ & 0,1 & 6 & $1,8 \%$ & $-0,1$ & 14 & $1,9 \%$ \\
\hline Total & 404 & $100 \%$ & & 332 & $100 \%$ & & 736 & $100 \%$ \\
\hline Sig: 0,176
\end{tabular}

Sig.: 0,176 | qui-quadrado: 12,704

Fonte: CPOP (2015)

De modo geral, observando os dados em sua totalidade, já que não há mudanças significativas, o primeiro dado indica uma concentração no uso de alguns formatos em 2014. Em 25,8\% dos segmentos predomina o pronunciamento do candidato, quando este 
A construção da campanha eleitoral majoritária no HGPE: uma análise comparada das estratégias usadas pelos presidenciáveis de 2014 - Michele Goulart Massuchin, Camilla Quesada Tavares, Fernanda Cavassana de Carvalho e Regiane Soares Lima

aparece fazendo alguma fala na propaganda. A cada quatro segmentos, um deles evidenciao candidato. Em segundo lugar, está o modelo de telejornal $(16,4 \%)$, que se aproxima da proposta do jornalismo, tentando gerar identificação entre o modelo de notícia com o de propaganda. Na sequência aparece o modelo de documentário $(15,4 \%)$, também aproximando a propaganda eleitoral de um modelo jornalístico, quase como uma espécie de grande reportagem televisiva (OLIVEIRA, 2005). Também se destacam vídeo clipes/jingles, representando 8,2\% dos segmentos, e ilustração/animação, em 10,9\% dos casos. Se a baixa segmentação poderia indicar menos produção nas campanhas televisivas, a evidência dos jingles e ilustrações demonstra o contrário, uma vez que são formatos que exigem maior elaboração da produção audiovisual.

Destaca-se também os $14,3 \%$ dos segmentos que reúnem depoimentos, seja de pessoas famosas ou o perfil de "povo fala", o que indica a presença de eleitores e lideranças no HGPE, mostrando que esta também é uma forma de compor a propaganda e angariar voto sem usar, necessariamente, a imagem do candidato. De modo geral, é expressivo o percentual de pronunciamento do candidato, um formato mais tradicional de propaganda eleitoral televisiva, mas, ao mesmo tempo, há outros mecanismos de compor a campanha que atornam mais dinâmica e, inclusive, mais próxima de um modelo semelhante ao telejornalismo, numa mescla dos formatos telejornal e documentário, o que confere maior legitimidade aos discursos (OLIVEIRA, 2005). Portanto, até aqui, a alteração percebida no que diz respeito à estruturação da campanha aparece só na extensão dos segmentos e não no modo como o conteúdo é apresentado aos eleitores, em que predominam os mesmos formatos ao longo do tempo.

\subsection{Quem aparece? A campanha na voz de candidatos, populares e personalidades}

De forma a complementar o estudo dos formatos, a tabela seguinte discute o orador dominante dos segmentos analisados, indicando diferenças nos dois períodos. Aqui o objetivo é verificar se houve mudanças no indivíduo que fala, ressaltando quem é utilizado para fazer a campanha televisiva. Observando os dados em sua totalidade, tem-se o predomínio do candidato e do locutor em off, este último muito utilizado no estilo dos documentários, já vistos acima, mesclando com a proposta do jornalismo e suas características inseridas no HGPE (ALBUQUERQUE, 2003; OLIVEIRA, 2005). 
Tabela 3. Orador predominante durante o primeiro e segundo turno

\begin{tabular}{l|c|c|c|c|c|c|c|c}
\hline & \multicolumn{3}{|c|}{ Primeiro turno } & \multicolumn{3}{c|}{ Segundo turno } & Total & \\
\hline & $\mathrm{N}$ & Perc. & R.p & $\mathrm{N}$ & Perc. & R.p. & $\mathrm{N}$ & Perc. \\
\hline Candidato & 122 & $30,2 \%$ & 0,7 & 87 & $26,2 \%$ & $-0,7$ & 209 & $28,4 \%$ \\
\hline Patrono político & 14 & $3,5 \%$ & 0,1 & 11 & $3,3 \%$ & $-0,1$ & 25 & $3,4 \%$ \\
\hline Garoto Propaganda & 37 & $9,2 \%$ & 0,9 & 21 & $6,3 \%$ & -1 & 58 & $7,9 \%$ \\
\hline Âncora & 29 & $7,2 \%$ & $-1,5$ & 41 & $12,3 \%$ & 1,7 & 70 & $9,5 \%$ \\
\hline Off_locutor & 118 & $29,2 \%$ & 0,6 & 85 & $25,6 \%$ & $-0,7$ & 203 & $27,6 \%$ \\
\hline Off_cantor & 19 & $4,7 \%$ & $-0,9$ & 24 & $7,2 \%$ & 1 & 43 & $5,8 \%$ \\
\hline Popular & 42 & $10,4 \%$ & 0,9 & 25 & $7,5 \%$ & -1 & 67 & $9,1 \%$ \\
\hline Personagem/ficção & 11 & $2,7 \%$ & 0,7 & 5 & $1,5 \%$ & $-0,8$ & 16 & $2,2 \%$ \\
\hline Personalidade & 4 & $1 \%$ & $-3,5$ & 31 & $9,3 \%$ & 3,8 & 35 & $4,8 \%$ \\
\hline Outros & 8 & $2 \%$ & 1,1 & 2 & $0,6 \%$ & $-1,2$ & 10 & $1,4 \%$ \\
\hline Total & 404 & $100 \%$ & & 332 & $100 \%$ & & 736 & $100 \%$ \\
\hline
\end{tabular}

Sig. 0,000 | qui-quadrado: 42,998

Fonte: CPOP (2015)

Em relação às mudanças,quando o orador é controlado pela variável turno, nota-se que são significativas $(0,000)$. Porém, observando os resíduos padronizados, tem-se apenas um deles significativo acima de $| \pm 1,96|$, que está relacionado à presença maior de personalidades reconhecidas do público. Estas tenderam a aparecer mais como oradores principais nos segmentos do segundo turno. É o caso, por exemplo, da presença da dupla Chitãozinho \& Xororó e dos ex-jogadores Ronaldo e Zico na campanha de Aécio Neves. De modo geral, os demais tipos de oradores se mantêm com poucas alterações de um turno ao outro, evidenciando poucas mudanças, de fato, no perfil de quem aparece na propaganda dos candidatos ao longo da campanha.

Após identificar que os segmentos se tornam mais longos, com mais presença de personalidades, e que os formatos se mantêm com pouca alteração durante a campanha, pelo menos quando comparados ambos os turnos, faz-se necessário observar como o conteúdo presente nesses formatos é apresentado. Isto é feito a partir da análise das estratégias, do apelo utilizado e da mensagem geral, que seguem no tópico seguinte. Ainda que pouco possa ser notado quanto à mudança estrutural, estimam-se maiores mudanças quanto ao conteúdo explorado ao longo do tempo, já que, para Lavareda (2009), há alterações da campanha em decorrência de fatos como pesquisas de opinião, escândalos políticos, etc.

Como as campanhas são construídas por estratégias que tem relação com a presença do candidato na disputa, assim como seu posicionamento e histórico (FIGUEIREDO et al, 1997; LAVAREDA, 
A construção da campanha eleitoral majoritária no HGPE: uma análise comparada das estratégias usadas pelos presidenciáveis de 2014 - Michele Goulart Massuchin, Camilla Quesada Tavares, Fernanda Cavassana de Carvalho e Regiane Soares Lima

2009), observa-se como estas aparecem na campanha e se há alterações nas mesmas ao longo do tempo, quando o cenário de campanha muda. Em 2014, se no primeiro turno havia uma disputa entre três candidatos - com a entrada de Marina Silva (PSB) - no segundoa disputa se torna ainda mais polarizada. Dessa forma, acredita-se que haja mudança na forma como os candidatos usam o HGPE para se apresentarem aos eleitores. Em primeiro lugar, destacase que os textos podem conter mais de uma estratégia, portanto observa-se o percentual total de casos em que aparece cada uma delas.

\subsection{Estratégias: da ênfase à carreira política ao discurso de mudanças}

Retomando a hipótese inicial, estima-se que, no que diz respeito às estratégias adotadas, a campanha torna-se mais negativa no segundo turno. Os estudos de Borba $(2012 ; 2015)$ indicam que os ataques são relevantes na conformação da propaganda eleitoral brasileira aparecendo numa média de $13 \%$ no primeiro turno e $21 \%$ no segundo, ao acompanhar os pleitos desde 1989 - inclusive observando também o fenômeno de uma campanha mais acirrada e, consequentemente, mais negativa ao longo do tempo. Em 2014, supõe-se que essa característica também tenha aparecido de forma enfática, marcando uma das principais mudanças entre as estratégias mais usuaisdo segundo turno.

Antes de comparar os dois períodos, destaca-se que determinadas estratégias também aparecem de modo mais evidente que outras, indicando que algumas delas são priorizadas em relação às demais no modo de conformação do HGPE. Cinco das 11 estratégias aparecem de modo mais frequentes: uso do cargo, associação à administração em disputa, apelo à mudança, ofensiva quanto a temas e ataque ao adversário. Entre as que aparecem de modo menos expressivo estão, por exemplo, menção ao partido e endosso de lideranças da sociedade organizada. Nota-se a opção pelo uso de lideranças políticas em detrimento da sociedade civil e pouco espaço aos partidos políticos, evidenciando resultados já apresentados por Cervi e Turgeon (2011). Em 2014 o HGPE não é utilizado para a formação da imagem do partido e tampouco para identificar relação entre partido e candidato. 
Tabela 4. Distribuição das estratégias entre primeiro e segundo turno

\begin{tabular}{l|c|c|c|c|c|c}
\hline & \multicolumn{3}{|c|}{ Primeiro turno } & \multicolumn{3}{c}{ Segundo turno } \\
\hline & $\mathrm{N}$ & Perc. & $\% /$ casos & $\mathrm{N}$ & Perc. & $\% /$ casos \\
\hline Uso do cargo & 154 & $21,1 \%$ & $\mathbf{4 4 , 8 \%}$ & 64 & $12,4 \%$ & $\mathbf{2 4 , 9 \%}$ \\
\hline Associação à adm. em disputa & 140 & $19,2 \%$ & $\mathbf{4 0 , 7 \%}$ & 58 & $11,2 \%$ & $\mathbf{2 2 , 6 \%}$ \\
\hline Associação à adm. outra esfera & 34 & $4,7 \%$ & $9,9 \%$ & 8 & $1,6 \%$ & $3,1 \%$ \\
\hline Endosso de lideranças políticas & 15 & $2,1 \%$ & $4,4 \%$ & 27 & $5,2 \%$ & $10,5 \%$ \\
\hline Endosso de lideranças Soc. Org. & 5 & $0,7 \%$ & $1,5 \%$ & 11 & $2,1 \%$ & $4,3 \%$ \\
\hline Menção ao partido coligação & 7 & $1 \%$ & $2 \%$ & 11 & $2,1 \%$ & $4,3 \%$ \\
\hline Endosso do patrono & 20 & $2,7 \%$ & $5,8 \%$ & 12 & $2,3 \%$ & $4,7 \%$ \\
\hline Apelo a mudanças & 84 & $11,5 \%$ & $\mathbf{2 4 , 4 \%}$ & 94 & $18,2 \%$ & $\mathbf{3 6 , 6 \%}$ \\
\hline Ofensiva quanto a temas & 218 & $29,9 \%$ & $\mathbf{6 3 , 4 \%}$ & 113 & $21,9 \%$ & $\mathbf{4 4 \%}$ \\
\hline Ataque à adm. em curso & 19 & $2,6 \%$ & $5,5 \%$ & 36 & $7 \%$ & $14 \%$ \\
\hline Ataque a adversário & 34 & $4,7 \%$ & $9,9 \%$ & 82 & $15,9 \%$ & $\mathbf{3 1 , 9 \%}$ \\
\hline Total & 730 & $100 \%$ & $212,2 \%$ & 516 & $100 \%$ & $200,8 \%$ \\
\hline
\end{tabular}

Fonte: CPOP (2015)

Por outro lado, fica evidente a ênfase a cargos políticos para demonstrar carreira e prática política, do mesmo modo em que há grandes chances de os candidatos se associarem a administração em curso, principalmente pela presença de incumbentes, como é o caso de Dilma Rousseff (FIGUEIREDO et al, 1997). Também tem destaque a discussão temática, como já salientado por Albuquerque (1999), como uma função do HGPE e do discurso de mudança. Este tem relação direta com as discussões sobre mundos possíveis propostas por Figueiredo et al (1997), em que isso tende a caracterizar e prevalecer nas campanhas, principalmente dos desafiantes, como era o caso de Aécio Neves, em 2014. Por fim, tem-se o uso também para campanha negativa, seguindo uma vertente de pesquisa já abordada por Lourenço (2009) e Borba (2012; 2015). Isso mostra que a propaganda não serve apenas para formar a imagem do candidato, mas também a dos adversários (ALBUQUERQUE, 1999; LAVAREDA, 2009).

Articulando a análise para comparar os dois períodos, percebem-se algumas alterações bastante significativas no uso das estratégias, pois há praticamente uma substituição de estratégias ao longo do tempo e não apenas o acréscimo da campanha negativa como se supunha na hipótese inicial. De modo específico, tem-se de fato um aumento evidente dos segmentos com ataques ao adversário, triplicando-os, e pouco mais que o dobro do ataque à administração. 0 aumento geral da campanha negativa vai de $15,4 \%$ no primeiro turno para $45 \%$ no segundo turno. Destaca-se que a pesquisa distingue o ataque direto ao adversário daquele direcionado à administração, sendo que os valores apresentados consideram a soma de ambos. Portanto, retomando a 
A construção da campanha eleitoral majoritária no HGPE: uma análise comparada das estratégias usadas pelos presidenciáveis de 2014 - Michele Goulart Massuchin, Camilla Quesada Tavares, Fernanda Cavassana de Carvalho e Regiane Soares Lima

hipótese, é possível dizer que, pelo menos no que diz respeito às estratégias, há evidência do aumento dos ataques no segundo turno.

Outro "achado" que os dados oferecem para além da confirmação de parte da hipótese inicial é de que há uma inversão nas estratégias utilizadas e não apenas a incorporação da campanha negativa. Até mesmo as estratégias que aparecem pouco tendem a ter mudança de um turno para outro, inclusive dobrando seu uso como é o caso de endosso de liderança ou menção aos partidos. No caso desta última, passa-se de $2 \%$ no primeiro turno e $4,3 \%$ no segundo. Notadamente, houve queda entre as principais estratégias como uso do cargo, associação à administração e ofensiva quanto a temas, mas com avanço dos ataques, como já discutido, e do apelo a mudanças e outras estratégias menos recorrentes. Até aqui, no que diz respeito às estratégias, é possível verificar diferenças relevantes na construção da propaganda na televisão: primeiro, centrada em temas, enfatizando a carreira política e o cargo em disputa, para depois focar nos ataques e no discurso de mudanças.

\subsection{Tipos de apelo: ideológico, emocional ou pragmático?}

De modo complementar, e também relacionado ao conteúdo, observa-se o apelo das mensagens, pois também indica o modo como a propaganda na televisão foi construída. 0 apelo tem a ver com o modo como o conteúdo é apresentado, muito próximo da linguagem utilizada para repassar o conteúdo da propaganda. De modo geral, torna-se predominante o apelo emocional aliado ao pragmático na campanha, em $41,4 \%$ e $36,3 \%$ dos segmentos, respectivamente. Formou-se, assim, uma campanha dividida, basicamente, em uma propaganda com foco no emocional do eleitor mesclado ao pragmatismo necessário, por exemplo, para discutir determinados temas. A tabela seguinte indica como o tipo de apelo utilizado se altera ao longo do tempo e como essa variação, condicionada pelo turno, mostra-se estatisticamente significativa, evidenciada pelo teste de qui-quadrado (sig. 0,000). 


\section{Tabela 5. Apelo utilizado nas mensagens do HGPE no primeiro e} no segundo turno

\begin{tabular}{|c|c|c|c|c|}
\hline & $\begin{array}{c}\text { Primeiro } \\
\text { turno }\end{array}$ & $\begin{array}{c}\text { Segundo } \\
\text { turno }\end{array}$ & Total \\
\hline \multirow[t]{3}{*}{ Pragmático } & $\mathrm{N}$ & 173 & 95 & 268 \\
\hline & Perc. & $42,8 \%$ & $28,6 \%$ & $36,4 \%$ \\
\hline & R.p & 2,1 & $-2,4$ & \\
\hline \multirow[t]{3}{*}{ Ideológico } & $\mathrm{N}$ & 10 & 25 & 35 \\
\hline & Perc. & $2,5 \%$ & $7,5 \%$ & $4,8 \%$ \\
\hline & R.p & $-2,1$ & 2,3 & \\
\hline \multirow[t]{3}{*}{ Político } & $\mathrm{N}$ & 52 & 37 & 89 \\
\hline & Perc. & $12,9 \%$ & $11,1 \%$ & $12,1 \%$ \\
\hline & R.p & 0,5 & $-0,5$ & \\
\hline \multirow[t]{3}{*}{ Emocional } & $\mathrm{N}$ & 144 & 161 & 305 \\
\hline & Perc. & $35,6 \%$ & $48,5 \%$ & $41,4 \%$ \\
\hline & R.p & $-1,8$ & 2 & \\
\hline \multirow{3}{*}{$\begin{array}{l}\text { Documental ou } \\
\text { Credibilidade da } \\
\text { fonte }\end{array}$} & $\mathrm{N}$ & 25 & 14 & 39 \\
\hline & Perc. & $6,2 \%$ & $4,2 \%$ & $5,3 \%$ \\
\hline & R.p & 0,8 & $-0,9$ & \\
\hline \multirow{2}{*}{ Total } & $\mathrm{N}$ & 404 & 332 & 736 \\
\hline & Perc. & $100 \%$ & $100 \%$ & $100 \%$ \\
\hline
\end{tabular}

Sig. 0,000 | qui-quadrado: 28,942

Fonte: CPOP (2015)

No primeiro turno, em termos absolutos, observa-se que o apelo pragmático é predominante em $42,8 \%$ dos segmentos. 0 apelo emocional aparece em segundo lugar, com $35,6 \%$. Já no segundo turno, o processo se inverte com menos evidência ao apelo pragmático, que aparece em 28,6\% das mensagens, e com destaque para o apelo emocional, que chega a 48,5\%. Além disso, percebe-se um aumento do discurso ideológico que, de $2,5 \%$, alcança $7,5 \%$ do total dos segmentos na última etapa da disputa. Isso indica, seguindo o que já vinha mostrando as estratégias, uma presença um pouco maior dos partidos no segundo turno, ainda que não seja algo tão evidente na campanha majoritária em questão.

Pelo menos em 2014, em função da polarização e do acirramento da disputa, pode ter havido um aumento gradativo do apelo ideológico também atrelado a ênfase em partidos. Isso pode ser relacionado com uma possibilidade de referência aos partidos ressaltada por Dias (2005) e também da ideologização do discurso político eleitoral em determinados momentos em que isso passa a ter mais relevância na disputa. Neste caso, foi relevante e ganhou espaço no segundo turno, 
A construção da campanha eleitoral majoritária no HGPE: uma análise comparada das estratégias usadas pelos presidenciáveis de 2014 - Michele Goulart Massuchin, Camilla Quesada Tavares, Fernanda Cavassana de Carvalho e Regiane Soares Lima

como indica o resíduo positivo de 2,3. Com isso, a hipótese inicial que supõe a maior presença de mensagens emocionais no final da campanha em relação ao início é confirmada, já que cresce o apelo emocional e, em contrapartida, cai em desuso o apelo pragmático.

\subsection{Mensagens: manutenção da imagem e detrimento da tematização}

Somando-se às analises, observa-se a distribuição da mensagem geral, que se relaciona com o objetivo central dos segmentos e o tema/objeto predominante. Ainda que trabalhos recentes tenham mostrado a ênfase na formação da imagem (CERVI e MASSUCHIN, 2011), no caso de 2014 percebe-se que $45 \%$ do total dos segmentos totais tiveram como objeto central temas de políticas públicas, o que está acima da ênfase na imagem do candidato, presente em $41 \%$ dos casos. Observando de modo comparado a análise exposta na tabela abaixo, percebe-se, assim como nos apelos, uma mudança significativa entre os dois turnos.

Tabela 6. Distribuição da mensagem geral entre primeiro e segundo turno

\begin{tabular}{|c|c|c|c|c|}
\hline & & $\begin{array}{c}\text { Primeiro } \\
\text { turno }\end{array}$ & $\begin{array}{l}\text { Segundo } \\
\text { turno }\end{array}$ & Total \\
\hline \multirow[t]{3}{*}{ Tema } & $\mathrm{N}$ & 218 & 113 & 331 \\
\hline & Percentual & $54 \%$ & $34 \%$ & $45 \%$ \\
\hline & R.p & 2,7 & -3 & \\
\hline \multirow[t]{3}{*}{ Imagem } & $\mathrm{N}$ & 154 & 148 & 302 \\
\hline & Percentual & $38,1 \%$ & $44,6 \%$ & $41 \%$ \\
\hline & R.p & $-0,9$ & 1 & \\
\hline \multirow[t]{3}{*}{ Metacampanha } & $\mathrm{N}$ & 32 & 71 & 103 \\
\hline & Percentual & $7,9 \%$ & $21,4 \%$ & $14 \%$ \\
\hline & R.p & $-3,3$ & 3,6 & \\
\hline \multirow[t]{2}{*}{ Total } & $\mathrm{N}$ & 404 & 332 & 736 \\
\hline & Percentual & $100 \%$ & $100 \%$ & $100 \%$ \\
\hline
\end{tabular}

Sig. 0,000 | qui-quadrado: 41,548

Fonte: CPOP (2015)

0 primeiro turno tem como objeto central, de fato, temas de políticas públicas (54\%), porém, no segundo, o tema perde destaque e a imagem torna-se mais recorrente, aparecendo em $44 \%$ dos segmentos do período. Ao fazer o teste de qui-quadrado, observa-se variação significativa entre as variáveis (sig. 0,000), indicando que há 
diferenças entre primeiro e segundo turno no que tange às mensagens utilizadas. No entanto, ao que tudo indica, os temas foram substituídos pelo aumento da metacampanha e não pelo aumento excessivo da formação da imagem.

Ao retomar parte da primeira hipótese, que supõe um avanço da formação de imagem no segundo turno, não é possível confirmar isso. Apenas se pode dizer que ela é ressaltada pela diminuição da tematização no HGPE. Ou seja, no decorrer da campanha, não é a ênfase na imagem que aumenta, mas a discussão de temas que perde força para a metacampanha, como indicam os resíduos padronizados. Ainda que, em termos absolutos, a mensagem destinada à formação de imagem torna-se majoritária no segundo turno, a sua variação ao longo do tempo não é significativa, sem resíduos altos e com uma distribuição mais próxima da "média" total. Isso mostra, de forma geral, que imagem tem certa centralidade em ambos os momentos, o que muda em relação à mensagem veiculada na propaganda é o foco nos temas, concentrado no primeiro turno, e na metacampanha, que se destaca no segundo.

A análise até aqui permite dizer que há poucas mudanças no que diz respeito a como o HGPE é estruturado - a partir da observação do tempo, orador e formato - e que as mudanças se concentram mais no que diz respeito ao conteúdo, quando se observa as estratégias, o apelo e a mensagem geral. A partir disso, a primeira hipótese de que há mudança na campanha do HGPE ao longo do tempo é confirmada parcialmente. Evidencia-se um segundo turno com mais ataques e mais emocional, porém não há aumento do foco da imagem, mas sim uma diminuição da tematização. 0 próximo tópico do trabalho voltará a análise para a comparação entre as duas candidaturas.

\section{HGPE e a construção da campanha de Dilma Rousseff e Aécio Neves em 2014}

Esta segunda etapa da análise tem por objetivo identificar as proximidades e divergências no discurso dos dois principais candidatos - Dilma Rousseff e Aécio Neves - com o intuito de confirmar ou refutar a hipótese apresentada na introdução, de que os candidatos possuem estratégias diferentes para aparecerem no HGPE. Isso se justificaria pela diferença na trajetória e histórico político de cada candidato, assim como pela posição oposta que ambos ocupam na disputa: um incumbente e outro desafiante. Como relata Lavareda (2009), isso é importante para demarcar a propaganda e o modo como os programas do HGPE são construídos. 
A construção da campanha eleitoral majoritária no HGPE: uma análise comparada das estratégias usadas pelos presidenciáveis de 2014 - Michele Goulart Massuchin, Camilla Quesada Tavares, Fernanda Cavassana de Carvalho e Regiane Soares Lima

\subsection{Distribuição do tempo, apelo e mensagem no HGPE dos candidatos}

Esta primeira tabela apresenta os dados quanto ao tempo, ao número de segmentos e as medidas de tendência central, a média e a mediana. Ainda que haja um padrão, já observado, nas diferenças do conteúdo da propaganda quando comparados os turnos da disputa, o objetivo aqui é mostrar as diferenças entre as campanhas dos dois candidatos, mantendo o controle por turno. Seguem os dados descritivos.

Tabela 7. Distribuição do tempo e média entre primeiro e segundo turno

\begin{tabular}{l|l|c|c|c}
\hline & & Dilma & Aécio & Total \\
\hline \multirow{3}{*}{$\begin{array}{l}\text { Primeiro } \\
\text { turno }\end{array}$} & $\mathrm{N}$ & 265 & 139 & 404 \\
\cline { 2 - 5 } & Media & 46,25 & 34,06 & 42,05 \\
\cline { 2 - 5 } & Mediana & 36 & 21 & 31 \\
\cline { 2 - 5 } & Desvio Padrão & 42,720 & 3806 & 41,540 \\
\cline { 2 - 5 } & Soma & 12255 & 4734 & 16989 \\
\hline \multirow{3}{*}{$\begin{array}{l}\text { Segundo } \\
\text { turno }\end{array}$} & $\mathrm{N}$ & 178 & 154 & 332 \\
\cline { 2 - 5 } & Media & 52,59 & 58,61 & 55,38 \\
\cline { 2 - 5 } & Mediana & 47,50 & 47,50 & 47,50 \\
\cline { 2 - 5 } & Desvio Padrão & 34,132 & 46,06 & 40,138 \\
\cline { 2 - 5 } & Soma & 9361 & 9026 & 18387 \\
\hline
\end{tabular}

Nota: Teste $\mathrm{T}$ de diferença de média para $1^{\circ}$ turno: 2,82 (sig.: 0,000 )

Teste $\mathrm{T}$ de diferença de média para $2^{\circ}$ turno: 1,36 (sig.: 0,173 ) Fonte: CPOP (2015)

Dilma tem segmentos mais longos no primeiro turno, com 46 segundos de média em relação a 34 segundos nos de Aécio, o que é uma diferença significativa, segundo o teste de independência de média. Contudo, o teste aplicado para o segundo turno, que possui segmentos claramente mais longos, evidencia uma diferença de média não significativa, havendo proximidade entre os candidatos. Isso quer dizer que, quanto à duração dos segmentos, as diferenças entre a propaganda de Dilma e Aécio só aparecem no primeiro turno.

Em termos de conteúdo, as diferenças aparecem em ambos os turnos, tanto no que diz respeito ao apelo, quanto na mensagem geral e nas estratégias. Os dados seguintes comparam a presença dos tipos de apelo por candidato e por turno e indicam diferenças significativas, 
com sig. de 0,000 tanto para o primeiro, quanto para o segundo turno. A campanha de Dilma é marcada, em ambos os turnos, pelo discurso pragmático, algo bem menos frequente na campanha de Aécio Neves, ainda que tenha havido uma queda se comparados os dois períodos (de $53 \%$ para $37 \%$ ). Aécio explora mais o apelo emocional em ambos os períodos (44\% e 61\%).

Tabela 8. Distribuição do apelo entre Dilma Rousseff e Aécio Neves

\begin{tabular}{l|l|r|r|r|r|r|r}
\hline \multicolumn{2}{c}{} & \multicolumn{3}{c|}{ Primeiro turno } & \multicolumn{3}{c}{ Segundo turno } \\
\cline { 3 - 8 } \multicolumn{2}{c}{} & Dilma & Aécio & Total & Dilma & Aécio & Total \\
\hline \multirow{2}{*}{ Pragmático } & Perc. & $53,2 \%$ & $23 \%$ & $42,8 \%$ & $37,6 \%$ & $18,2 \%$ & $28,6 \%$ \\
\cline { 2 - 8 } & R.p & $\mathbf{2 , 6}$ & $-3,6$ & & $\mathbf{2 , 3}$ & $-2,4$ & \\
\hline \multirow{2}{*}{ Ideológico } & Perćtico & $3 \%$ & $1,4 \%$ & $2,5 \%$ & $9,6 \%$ & $5,2 \%$ & $7,5 \%$ \\
\cline { 2 - 8 } & R.p & 0,6 & $-0,8$ & & 1 & $-1,1$ & \\
\hline \multirow{2}{*}{ Emocional } & Perc. & 8,7 & 20,9 & $12,9 \%$ & $12,9 \%$ & $9,1 \%$ & $11,1 \%$ \\
\cline { 2 - 8 } & R.p & $-1,9$ & $\mathbf{2 , 6}$ & & 0,7 & $-0,8$ & \\
\hline \multirow{2}{*}{$\begin{array}{l}\text { Documental ou } \\
\text { Credibilidade } \\
\text { da fonte }\end{array}$} & Perc. & $30,9 \%$ & $44,6 \%$ & $35,6 \%$ & $37,1 \%$ & $61,7 \%$ & $48,5 \%$ \\
\cline { 2 - 8 } & R.p & $-1,3$ & 1,8 & & $-2,2$ & $\mathbf{2 , 4}$ & \\
\hline Total & R.p & $-1,2 \%$ & $10,1 \%$ & $6,2 \%$ & $2,8 \%$ & $5,8 \%$ & $4,2 \%$ \\
\hline
\end{tabular}

Primeiro turno: Sig. 0,000 qui-quadrado: 40,776

Segundo turno: sig. 0,000 qui-quadrado: 26,208

Fonte: CPOP (2015)

No entanto, as diferenças significativas entre ambos estão na força da proximidade de apelo pragmático e Dilma (resíduos de 2,6 e 2,3), ao contrário de Aécio (-3,6 e -2,4), e também no uso maior que o candidato do PSDB faz do apelo político no primeiro turno (resíduo de 2,6) e do apelo emocional no segundo (resíduo de 2,4). De fato, há queda no pragmatismo ao longo do tempo, mas Dilma continua marcada por ele.

0 aumento do discurso ideológico se distribui de modo semelhante entre os dois candidatos em ambos os turnos e cresce de forma parecida, cerca de duas vezes mais para cada um. Isso mostra que evidenciar as ideologias, pelo menos nesta disputa mais polarizada, foi algo que permeou as duas campanhas. Já o apelo emocional, que cresce no segundo turno, tende a estar muito mais próximo de Aécio que valorizou mais o uso deste apelo do que Dilma. No segundo turno, Dilma fez uma campanha dividida entre os apelos pragmático e 
A construção da campanha eleitoral majoritária no HGPE: uma análise comparada das estratégias usadas pelos presidenciáveis de 2014 - Michele Goulart Massuchin, Camilla Quesada Tavares, Fernanda Cavassana de Carvalho e Regiane Soares Lima

emocional, enquanto Aécio enfatizou mais a emoção. De modo geral, Dilma sempre teve um apelo mais pragmático em relação a Aécio.

Como já foi identificado no tópico anterior, o segundo turno deixa a tematizaçãode lado, mas condicionado principalmente pelo aumento de metacampanha, enquanto a imagem apareceu em ambos os turnos com poucas modificações. Como exposto na tabela abaixo, ao se olhar as diferenças entre Dilma e Aécio quanto à mensagem geral, observa-se que o aumento da metacampanha ocorre de forma similar, sem diferenciações entre os candidatos. Já em relação à tematização, há de fato queda no segundo turno, mas destaca-se, porém, que Dilma seguiu uma campanha que teve a discussão de políticas e propostas como carro chefe (com variação de $22,1 \%$ ao passar de $67 \%$ para 44,9\%) em comparação aos demais tipos de mensagem geral e também ao candidato concorrente, o que é enfatizado pelos resíduos positivos significativos $(2,9$ e 2,5$)$ nos dois momentos. Aécio, por outro lado, seguiu a campanha com foco na formação da imagem (61\% e 54\%), o que também é ressaltado pelos resíduos padronizados $(4,5$ e 1,9).

Tabela 9. Distribuição da mensagem geral dentre Dilma Rousseff e Aécio Neves

\begin{tabular}{l|l|r|r|r|r|r|r}
\hline \multirow{2}{*}{} & \multicolumn{3}{|c|}{ Primeiro turno } & \multicolumn{3}{c}{ Segundo turno } \\
\cline { 3 - 8 } & & Dilma & Aécio & Total & Dilma & Aécio & Total \\
\hline \multirow{2}{*}{ Tema } & Percentual & $67,2 \%$ & $28,8 \%$ & $54 \%$ & $44,9 \%$ & $21,4 \%$ & $34 \%$ \\
\cline { 2 - 8 } & R.p. & $\mathbf{2 , 9}$ & -4 & & $\mathbf{2 , 5}$ & $-2,7$ & \\
\hline \multirow{2}{*}{ Imagem } & Percentual & $25,7 \%$ & $61,9 \%$ & $38,1 \%$ & $36 \%$ & $54,50 \%$ & $44,6 \%$ \\
\cline { 2 - 8 } & R.p. & $-3,3$ & $\mathbf{4 , 5}$ & & $-1,7$ & $\mathbf{1 , 9}$ & \\
\hline \multirow{2}{*}{ Metacampanha } & Percentual & $7,2 \%$ & $9,4 \%$ & $7,9 \%$ & $19,1 \%$ & $24,00 \%$ & $21,4 \%$ \\
\cline { 2 - 8 } & R.p. & $-0,4$ & 0,6 & & $-0,7$ & 0,7 & \\
\hline \multirow{2}{*}{ Total } & Percentual & $100 \%$ & $100 \%$ & $100 \%$ & $100 \%$ & $100 \%$ & $100 \%$ \\
\hline
\end{tabular}

Primeiro turno: sig. 0,000 | qui-quadrado: 56,816

Segundo turno: sig. 0,000 | qui-quadrado: 20,752

Fonte: CPOP (2015)

Em geral, têm-se, então, diferenças também quanto à mensagem geral quando se compara os candidatos. Dilma forma sua campanha mais focada na tematização, o que se relaciona, também, com sua ênfase num discurso mais pragmático. Apesar de ser uma candidata incumbente, tende a focar a campanha nos temas de políticas públicas, contribuindo para equilibrar a visão que se tem do HGPE focado na imagem do candidato (CERVI e MASSUCHIN, 2011). Por outro lado, Aécio Neves se utiliza da formação da imagem como carro chefe ao 
longo de todo o período, mesmo sendo senador e já tendo uma carreira política relativamente sólida. Por fim, resta analisar como se distribuem as estratégias entre cada um dos candidatos nos dois turnos, observando se, para ambos, ocorre a inversão percebida anteriormente, principalmente do aumento da campanha negativa e da diminuição da associação à administração em disputa, da ofensiva a temas e do uso do cargo - estas variáveis mais recorrentes, mas que apareceram menos no último turno.

\subsection{As diferenças nas estratégias discursivas de Dilma e Aécio}

O gráfico abaixo apresenta os dados referentes aos resíduos padronizados para a presença de cada uma das estratégias em relação a ambos os candidatos e a tendência de se associarem a tal característica. Os dados do primeiro turno indicam que duas características se sobressaem na campanha de Dilma em oposição à campanha de Aécio: associação à administração em disputa e ofensiva quanto a temas (resíduos de 4,3 e 2,9, respectivamente). Esses dados indicam bastante sobre o posicionamento de Dilma na disputa: incumbente que não ataca a administração e se associa a ela de modo positivo, assim como também não pede por mudanças.

\section{Gráfico 1. Estratégias mais utilizadas pelos candidatos no primeiro turno}

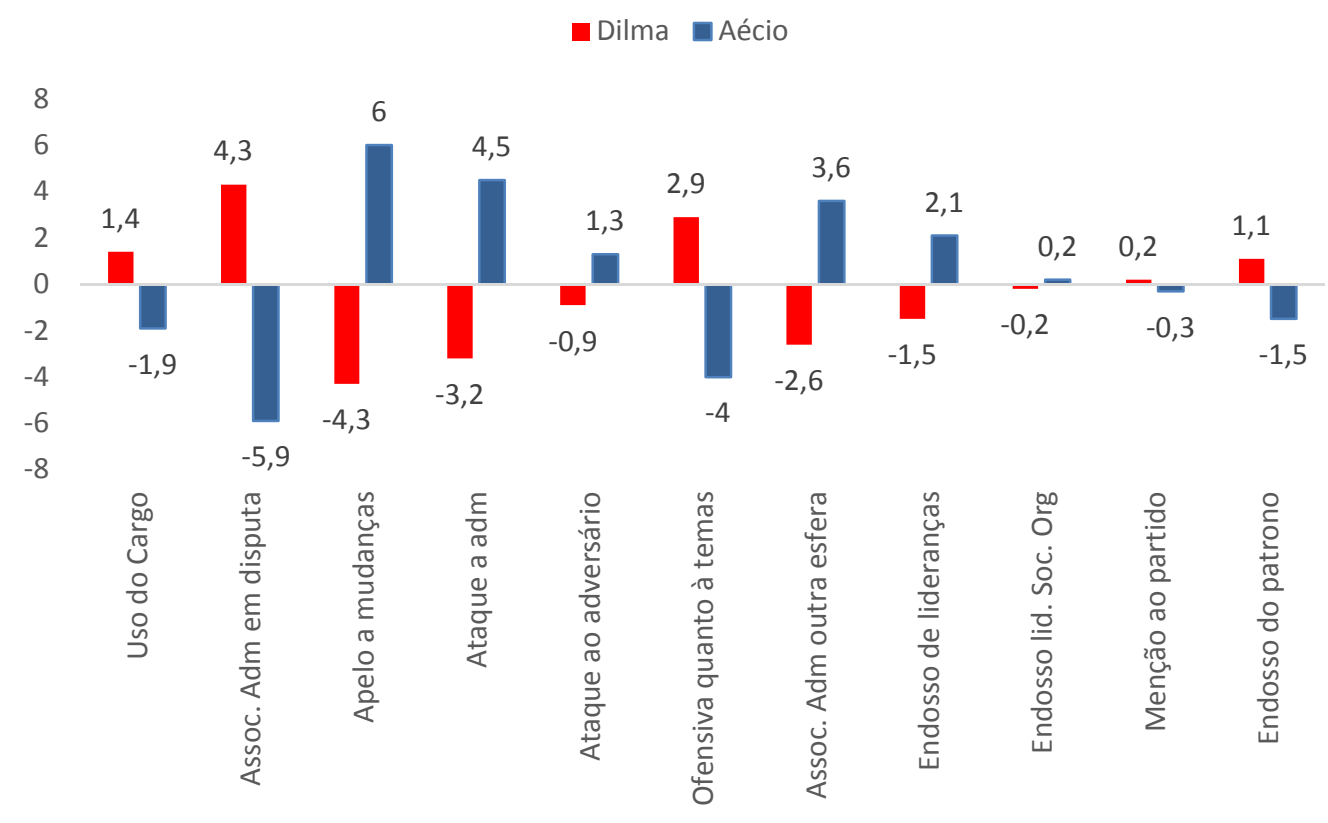

Fonte: CPOP (2015) 
A construção da campanha eleitoral majoritária no HGPE: uma análise comparada das estratégias usadas pelos presidenciáveis de 2014 - Michele Goulart Massuchin, Camilla Quesada Tavares, Fernanda Cavassana de Carvalho e Regiane Soares Lima

Esses dados seguem basicamente os pressupostos teóricos discutidos por Figueiredo et al (1997) quanto ao uso e apropriação de estratégias. A única característica menos usual de Dilma enquanto incumbente é sua ênfase em temas, o que normalmente é papel de partidos menores ou de desafiantes que enfatizam novas políticas públicas. Aqui, ao que tudo indica, Dilma se destaca como candidata que tematizou a agenda eleitoral, pelo menos no HGPE.

Em relação ao candidato Aécio Neves, as estratégias que mais apareceram em sua campanha no primeiro turno, diferenciando-se de Dilma Rousseff foram: apelo a mudanças, ataque à administração, endosso de lideranças e associação a outras administrações. Notadamente características que evidenciam seu papel de oposição ao governo, principalmente pela ênfase na mudança e também nos ataques à administração. Notadamente, Aécio não dá ênfase aos temas de campanha nem como estratégia.

o que chama a atenção é que o ataque ao adversário tende a aparecer de modo muito similar entre Dilma e Aécio. No geral, foram 9,9\% de segmentos de ataque direto no primeiro turno, característica evidenciada com percentuais semelhantes quando observadas as campanhas de cada um dos candidatos. Portanto, o que seria uma característica típica de desafiante - conforme relatam Figueiredo et al (1997)- aparece também na campanha da incumbente em 2014, ainda no primeiro turno. 0 acirramento da disputa, principalmente em relação à Marina Silva em alguns momentos do primeiro turno, pode contextualizar esse dado, mas ainda assim difere-se do esperado.

Assim como podem ter mudado as estratégias predominantes, também pode haver outras diferenças entre os candidatos no segundo momento da disputa, quando esta ganha ares de polarização entre PT e PSDB, com a saída de Marina Silva (PSB). No segundo turno, as maiores associações para a campanha de Dilma apresentam-se as mesmas do primeiro turno - ofensiva quanto a temas e associação a administração em disputa - com o acréscimo de uso do cargo. Como já esperado, Dilma continua distante de apelo à mudança, esta estratégica típica da campanha da oposição. 


\section{Gráfico 2. Estratégias mais utilizadas pelos candidatos no segundo turno}

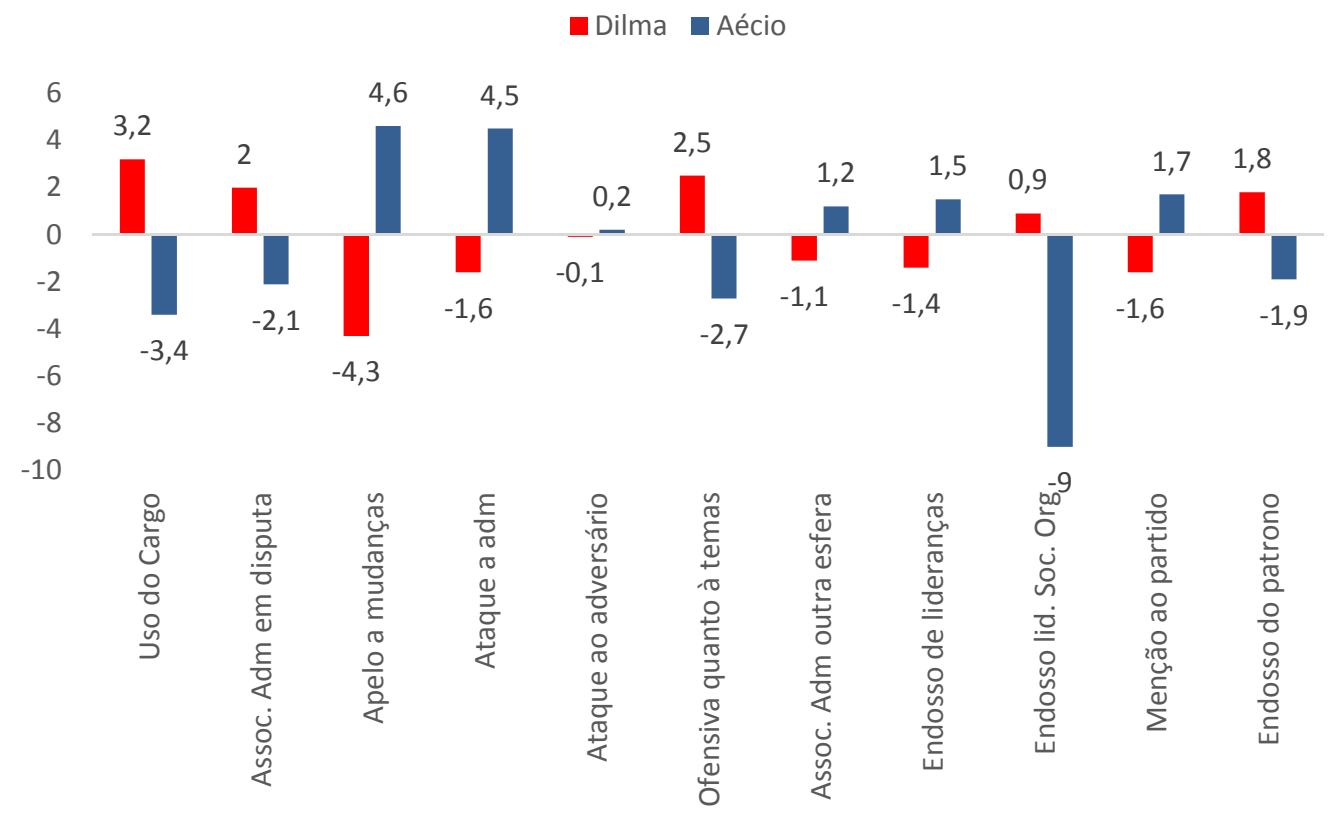

Fonte: CPOP (2015)

Já em relação à campanha de Aécio Neves, nota-se a mesma tendência de diferenciar-se de Dilma por meio do apelo a mudança e ataque à administração - uma ênfase típica de campanha de oposição no segundo turno que repete uma versão já evidenciada no primeiro momento. No entanto, não há mais ênfase quanto ao uso de lideranças e associação a outras esferas, algo que Aécio fazia mais vezes que Dilma no primeiro turno, principalmente retomando sua carreira política.

Novamente o ataque ao adversário que deveria diferenciar a campanha de Aécio de Dilma não ocorre, pois ambos usam de modo muito similar a estratégia, da mesma forma que durante o primeiro turno. A ênfase em ataques, como foi mencionada anteriormente, aumenta bastante no segundo turno, mas de modo muito similar para ambos os candidatos. 0 esperado seria uma ênfase maior de ataques para a oposição, já que é típica de desafiante (FIGUEIREDO et al, 1997).

Unindo os dados dos dois turnos e observando as marcas de estratégias típicas de cada candidato pode-se destacar a ênfase em temas, uso do cargo e associação à administração em disputa, como sendo as diferenças de Dilma em relação ao seu opositor. Aécio, por outro lado, diferencia-se por usar ataque aos adversários, apelo à 
A construção da campanha eleitoral majoritária no HGPE: uma análise comparada das estratégias usadas pelos presidenciáveis de 2014 - Michele Goulart Massuchin, Camilla Quesada Tavares, Fernanda Cavassana de Carvalho e Regiane Soares Lima

mudança e associação a outras esferas. Nas demais estratégias, há pouca diferença entre eles. Retoma-se a hipótese inicial, confirmando diferenças na maneira como os candidatos se apropriam deste espaço, pois cada um deles apresenta suas marcas e características, diferenciando-se do concorrente, ainda que a ênfase a ataques não seja uma distinção.

\section{Conclusão}

Este artigo teve por objetivo identificar as diferenças estratégicas presentes no conteúdo produzido para o Horário Gratuito de Propaganda Eleitoral (HGPE) das campanhas de Dilma Rousseff (PT) e Aécio Neves (PSDB) em 2014. Observando e comparando os dois turnos da disputa, teve-se por base duas hipóteses a serem respondidas ao longo da análise. De início percebe-se que há poucas mudanças ao longo do tempo em relação ao formato, que é algo mais homogêneo. Dentre os mais utilizados apareceram o pronunciamento do candidato, telejornal, documentário, animação e videoclipe/jingle.

Conforme apontou Albuquerque (2003) e Oliveira (2009), os formatos ligados ao jornalismo trazem mais credibilidade e legitimidade ao discurso, o que pode explicar a forte presença de formatos desse gênero, como o telejornal e documentário. Sobre a presença do videoclipe/jingle entre os principais formatos, Ferrari (2011) argumenta que ele é um recurso interpretativo da mensagem política, observado como elemento colaborativo para compreensão, tendo sua função para além de cultivar as emoções do eleitor.

Em relação a primeira hipótese, está é parcialmente confirmada. 0 pressuposto inicial de que a campanha televisiva passa a ser mais emocional ao longo do tempo foi confirmada, já que há aumento do apelo emocional e queda do uso do apelo pragmático. No entanto, não se confirma o aumento no foco da imagem, como se imaginava. 0 que se verifica é a diminuição da tematização dos segmentos, enquanto há o aumento de abordagens relativas à metacampanha.

Dessa forma, ao se afirmar que o HGPE tem sido mais temático, como Massuchin e Tavares (2014) fazem para o caso de Curitiba em 2012, é preciso ter cautela. Em 2014 há centralidade no HGPE enquanto tematizador do período eleitoral, mas apenas no início da campanha. Houve também aumento dos ataques como se esperava, mas também uma mudança geral na presença de outras estratégias. Até aqui tem-se primeiro uma campanha centrada em temas, enfatizando a carreira política e o cargo em disputa, para depois focar nos ataques e no discurso de mudanças. 
A análise também demonstra que há diferenças nas estratégias dos candidatos. Unindo os dados dos dois turnos e observando as marcas de estratégias típicas de cada candidato, pode-se destacar a ênfase em temas, uso do cargo e associação à administração em disputa, como sendo as diferenças de Dilma em relação ao seu opositor. Aécio, por outro lado, diferencia-se por usar ataque aos adversários, apelo à mudança e associação a outras esferas.

As principais estratégias observadas entre as campanhas de Dilma Rousseff e Aécio Neves vão de encontro com as apresentadas por Figueiredo et al (1997) pelo tipo de posição que o candidato possui no pleito - incumbente ou desafiante. Ambos os candidatos incorporaram, em seus programas, as estratégicas tipicamente utilizadas em cada caso. Isso demonstra, ainda, que há diferenças na maneira como os candidatos produzem o conteúdo do HGPE, confirmando nossa segunda hipótese.

\section{Referências}

ALBUQUERQUE, A. Aqui você vê a verdade na tevê: a propaganda política na televisão. Niterói: Universidade Federal Fluminense, 1999.

. 0 anfitrião ausente: a televisão nos estudos sobre propaganda política na televisão. Texto apresentado no XII Encontro Anual da Compós, Recife, 2003.

.; STEIBEL, F.; CARNEIRO, C. A Outra Face do Horário Gratuito: Partidos Políticos e Eleições Proporcionais na Televisão. Dados - Revista de Ciências Sociais, Rio de Janeiro, v. 51, n. 2, p.459-487, 2008.

ALDÉ, A.; CHAGAS, V.; SANTOS, J. G. Teses e dissertações defendidas no Brasil (1992-2012): um mapa da pesquisa em comunicação e política 2013. Revista Compolítica, vol. 2, núm.3, 2013.

ALMEIDA, J. Apelos eleitorais no HEGTV da campanha presidencial de 2006. Texto apresentado no II Encontro da Compolítica, Belo Horizonte, 2007.

BORBA, F. A propaganda negativa: estratégias e voto nas eleições brasileiras. 2012. 198 f. Tese (Doutorado em Ciência Política) - Instituto de Estudos Sociais e Políticos, Universidade do Estado do Rio de Janeiro, Rio de Janeiro. 2012.

Propaganda negativa nas eleições presidenciais brasileiras. Opinião Pública, Campinas, vol. 21, núm. 2, p. 268-295. 2015.

BENOIT, W. LESHNER, G; CHATTOPADHYAY, S. A Meta-Analysis of Political Advertising. Human Communication, v.10, n.4, 2007.

CARREIRÃO, Y. A eleição presidencial brasileira de 2006: uma análise preliminar. Política \& Sociedade, Florianópolis, vol. 6, núm. 10, p. 91-116. 2007. 
A construção da campanha eleitoral majoritária no HGPE: uma análise comparada das estratégias usadas pelos presidenciáveis de 2014 - Michele Goulart Massuchin, Camilla Quesada Tavares, Fernanda Cavassana de Carvalho e Regiane Soares Lima

CARVAlHo, V. As estratégias do Horário Gratuito de Propaganda Eleitoral - TV das campanhas de Jaques Wagner e Paulo Souto nas eleições de 2006. 2007. 114 f. Dissertação (Mestrado profissional em Administração) Escola de Administração, Universidade Federal da Bahia. 2007.

CERVI, E. O "tempo da política" e distribuição dos recursos partidários: uma análise do HGPE. Em Debate, Belo Horizonte, v.2, n.8, p. 12-17, 2010.

. O uso do HGPE como recurso partidário em eleiçõesproporcionais no Brasil: um instrumento de análise de conteúdo. Opinião Pública, Campinas, v. 17, n. 1, p.106-136, 2011.

; MASSUCHIN, M. HGPE e formação da opinião pública no Brasil: Análise das estratégias dos principais candidatos à presidência da república em 2010. IV Congresso Latino Americano de Opinião Pública da WAPOR. Belo Horizonte - MG, 2011.

;_____ TAVARES, C. Agenda da mídia, dos políticos e do público na campanha eleitoral de 2010. Revista Debates, Porto Alegre, vol. 6, núm. 1, p. 237-261. 2012.

COLling, L. 0 "estado da arte" dos estudos sobre mídia e eleições presidenciais de 1989 a 2002. In: Anais do XVI Encontro da Compós. Curitiba, 2007.

DE LA TORRE, C. The hybridcampaign: Traditional and modernity in Ecuador's 2006 Presidential Election. International Journal of Press/Politics, vol. 14, núm. 3, p. 335-352. 2009.

DIAS, M. Projeção da imagem partidária nas estratégias de campanha na televisão: uma análise do HGPE 2002. Dados - Revista de Ciências Sociais, Rio de Janeiro, v. 48, n. 1, p. 149-187. 2005.

Coadjuvantes no próprio espetáculo: os partidos políticos na propaganda eleitoral brasileira. In: 33o Encontro Anual da ANPOCS, Caxambu - MG, 2009.

. Campanha dialógica, pseudo-dialógica ou um "diálogo de surdos":uma proposta teórico-metodológica de análise das candidaturas presidenciais no Horário Gratuito de Propaganda Eleitoral. Texto apresentado no IX Encontro da ABCP, Brasília, 2014.

FERRARI, M. O melodrama como olhar interpretativo das campanhas eleitorais na TV. Texto apresentado no IV Encontro da Compolítica, Rio de Janeiro, 2011.

FIGUEIREDO, M. A Decisão do Voto: Democracia e Racionalidade. Belo Horizonte: Editora UFMG, 2008.

et al. Estratégias de persuasão eleitoral: uma proposta metodológica para o estudo da propaganda eleitoral. Opinião Pública, Campinas, vol. IV, núm. 3, p. 182-2013. 1997.

Intenção de voto e propaganda política: efeitos da propaganda eleitoral. Logos, 14: 9-20. 2007. 
GOMES, N. Formas persuasivas de comunicação política. 2. ed. Porto Alegre: EDIPUCRS, 2001. 135 p.

HOLTZ-BACHA, C; et al. Advertising for Europe TV Ads During the 2009 European Election Campaign in Four Countries. Nordicom Review, v. 33, n.2, 2012, p.77-99. 2012.

LAVAREDA, A. Emoções Ocultas e Estratégias Eleitorais. Rio de Janeiro: Objetiva, 2009. 311 p.

LOURENÇO, L. Propaganda negativa: ataques versus votos nas eleições presidenciais de 2002. Opinião Pública, Campinas, vol. 15, núm. 1, p. 133158. 2009.

MACHADO, M. A retórica da reeleição: mapeando os discursos dos Programas Eleitorais (HGPE) em 1998 e 2006. Opinião Pública, Campinas, vol.15, núm.1, p.159-189. 2009.

MAIR, P. Os partidos políticos e a democracia. Análise Social, vol. 38, p.277293. 2003.

MANCINI, P.; SWANSON, D. Politics, Media and Modern Democracy: an International Study of Innovations in Electoral Campaigning and their Consequences.Westport, London: Praeger, 1995.

MASSUCHIN, M. G.; TAVARES, C. Q. Convergência ou independência de conteúdo? Uma análise comparativa das estratégias eleitorais empregadas em websites de candidatos e no HGPE. In: Anais do 38 Encontro Anual da ANPOCS, 2014, Caxambu.

MIGUEL, L. F. Discursos cruzados: telenoticiários, HPEG e a construção da agenda eleitoral. Revista Sociologias. N. 11, ano 6, pp. 238-258. Porto Alegre, 2004.

Televisão e construção da agenda eleitoral no Brasil. Diálogos latinoamericanos. N. 10, pp. 1-16. Aarhus, 2005.

Apelos discursivos em campanhas proporcionais na televisão. Política \& Sociedade, vol. 9, n. 16, p. 151-175. 2010.

NORRIS, P. Political Communications and Democratic Politics. In: BARTLE, J; GRIFFITHS, D. Political Communication Transformed: From Morrison to Mandelson. Basingstoke: Macmillan, 2004.

OLIVEIRA, C. Horário gratuito político eleitoral - HGPE: o eleitor e a cidadania política. 2008. 368 f. Tese (Doutorado em Comunicação Social) Faculdade dos meios de comunicação social, Pontifícia Universidade Católica do Rio Grande do Sul, Porto Alegre. 2008.

OLIVEIRA, L. A importância da mídia nas disputas eleitorais: as estratégias para 2010. Em Debate, Belo Horizonte, vol. 2, núm. 8, p. 18-23, 2010.

OLIVEIRA, S. Palanque eletrônico: O Horário Gratuito de Propaganda Eleitoral e os gêneros do telejornalismo. 2005. 264 f. Dissertação (Mestrado em Comunicação) - Centro de Artes e Comunicação, Universidade Federal de Pernambuco, Recife. 2005. 
A construção da campanha eleitoral majoritária no HGPE: uma análise comparada das estratégias usadas pelos presidenciáveis de 2014 - Michele Goulart Massuchin, Camilla Quesada Tavares, Fernanda Cavassana de Carvalho e Regiane Soares Lima

PANKE, L.; CERVI, E. Análise da comunicação eleitoral: uma proposta metodológica para os estudos do HGPE. Revista Contemporânea Comunicação e Cultura, Salvador, v. 9, n. 3, p. 390-404. 2011.

et al. 0 que os candidatos à Presidência do Brasil falaram nos programas do HGPE, nas últimas eleições? Texto apresentado no IV Encontro da Compolítica, Rio de Janeiro, 2011.

PETHS, L. Horário gratuito de propaganda eleitoral e propaganda partidária gratuita: do surgimento à personalização na televisão brasileira. Anuário Unesco/Metodista de Comunicação Regional, ano 17, núm. 17, p. 63-76. 2013.

PORTO, M.; GUAZINA, L. Os "apelos" dos candidatos na eleição presidencial de 1994: análise do horário eleitoral gratuito. Texto apresentado no IV Encontro Anual da Compós, Brasília, 1995.

REIS, A. A dança dos números: o impacto das pesquisas eleitorais nas estratégias de comunicação do HGPE nas eleições de 2000 em São Paulo. Texto apresentado ao XXVI Congresso Brasileiro de Ciências da Comunicação, Belo Horizonte - MG, 2003.

RUBIM, A. Espetacularização e Mediatização da Política. In: RUBIM, A. (org). Comunicação e Política: conceitos e abordagens. Salvador: Edufba, 2004, p. 181-222.

SCHMITT, R.; CARNEIRO, L.; KUSCHNIR, K. Estratégias de campanha no Horário Gratuito de Propaganda Eleitoral em eleições proporcionais. Dados, Rio de Janeiro, vol. 42, núm. 2. 1999.

SOARES, M. Construindo o significado do voto: retórica da propaganda política pela televisão. 1995. $171 \mathrm{f}$. Tese (Doutorado em Comunicação Social) - Escola de Comunicações e Artes, Universidade de São Paulo, São Paulo. 1995.

SOUZA, N.; CERVI, E.; SANTOS, S. Mídia e eleições em Curitiba: estratégias discursivas do PT e do PSDB em 2004 e 2008. Texto apresentado no III Encontro da Compolítica, 2009.

TAVARES, C. Q. Para Presidente, Vote na gente. 2013. 121 f. Dissertação (Mestrado em Ciências Sociais Aplicadas) - CIPP, Universidade Estadual de Ponta Grossa, Ponta Grossa. 2013

VEIGA, Luciana F. Em busca de razões para o voto: o uso que o eleitor faz da propaganda política. Revista Contracampo, vol. 7, p. 183-208. 2003.

Recebido em 02 de novembro de 2015

Aprovado em 27 de novembro de 2015 


\title{
Presidential campaign in free campaign advertising time on Brazilian television: a comparative analysis of the strategies used by the 2014 candidates
}

\begin{abstract}
This paper aims to discuss the differences in the appropriation of the free campaign advertising time on brazilian television (HGPE) by parties and candidates in the majoritarian contest the presidency in 2014. The television advertising is the main campaign feature used by candidates in large electoral disputes, with both the content and the format are relevant to understand how the dispute is structured. It analyzes the content displayed by the two main candidates - Dilma Rousseff (PT) and Aécio Neves (PSDB) - the television campaign, considering the strategies, the appeal, the formats, type of speaker and the overall message of the campaign. The methodology used is quantitative content analysis. The analysis is built based on two assumptions: a) the runoff becomes more negative, with greater emphasis on the candidate's image, with a more focused campaign to the emotions than to pragmatism; b) structuring the campaign both candidates occurs differently, showing different characteristics and formats.
\end{abstract}

Keywords: 2014 elections; free campaign advertising time; campaign strategies 